\title{
Poverty, social inequality and mental health
}

\author{
Vijaya Murali \& Femi Oyebode
}

\begin{abstract}
The World Health Organization has described poverty as the greatest cause of suffering on earth. This article considers the direct and indirect effects of relative poverty on the development of emotional, behavioural and psychiatric problems, in the context of the growing inequality between rich and poor. The problems of children in particular are reviewed. Targets to reduce inequality have been set both nationally and internationally.
\end{abstract}

This is the fourth in a series of papers on the mental health of marginal groups. Previous papers have considered the effects of asylum-seeking and refugee status on mental health (Tribe, 2002), the implications for UK psychiatric services of young refugees who have fled from chronic civilian strife (Hodes, 2002) and the mental health of nurses in the UK (Nolan \& Smojkis, 2003)

In Bridging the Gaps, the World Health Organization (1995) states, 'The world's most ruthless killer and the greatest cause of suffering on earth is extreme poverty.' This statement emphasises the importance of poverty as a variable adversely influencing health. Poverty is a multidimensional phenomenon, encompassing inability to satisfy basic needs, lack of control over resources, lack of education and poor health. Poverty can be intrinsically alienating and distressing, and of particular concern are the direct and indirect effects of poverty on the development and maintenance of emotional, behavioural and psychiatric problems.

The measurement of poverty is based on incomes or consumption levels, and people are considered poor if their consumption or income levels fall below the 'poverty line', which is the minimum level necessary to meet basic needs. It should be emphasised that for the analysis of poverty in a particular country, the World Bank bases the poverty line on the norms for that society.

It is a well-recognised fact that poverty has important implications for both physical and mental health. In this article we discuss the impact of poverty on mental health, and explore possible explanations for the relationship between the two. It is vital to distinguish between absolute and relative poverty; even in countries where families generally have access to sufficient resources to maintain life, many are living in disadvantageous circumstances with poor housing, diet and amenities that do not live up to the expectations of society in general (Townsend, 1979).

\section{Poverty and social inequality}

The gulf between the poor and rich of the world is widening. Within the UK, the financial gap between the wealthy and the poor is not narrowing and differences in health between social classes I and V are becoming greater (Smith et al, 1990). Poverty and social inequality have direct and indirect effects on the social, mental and physical well-being of an individual. It is important to note that poverty and inequality are closely linked. Wilkinson (1997) believed that income inequality produces psychosocial stress, which leads to deteriorating health and higher mortality over time. However, the association between income inequality and life expectancy is slowly disappearing and is no longer widely accepted. Those who live in deprived communities, where there is underinvestment in the social and physical infrastructure, experience poor health, resulting in higher mortality for those of lower socio-economic class. The effects of income inequality also spill over into society, causing stress, frustration and family disruption, which then increase the rates of crime, homicide and violence (Wilkinson, 1996).

There are several obstacles, deficits and threats to health inherent in poverty. It is the poor who are exposed to dangerous environments, who (if employed) often have stressful, unrewarding and depersonalising work, who lack the necessities and

Vijaya Murali is a specialist registrar in general adult psychiatry (Cossham Hospital, Lodge Road, Kingswood, Bristol BS15 1LF, UK. E-mail: Lmurali@aol.com), with special interests in alcohol and substance misuse, and psychiatric intensive care. Current research includes a study of sleep disturbance in alcohol dependence. Femi Oyebode is Professor of Psychiatry at the Queen Elizabeth Psychiatric Hospital, Birmingham. 
amenities of life and who, because they are not part of the mainstream of society, are isolated from information and support. The inverse association between socio-economic level and risk of disease is one of the most pervasive and enduring observations in public health (Kaplan et al, 1987). It has been known for a long time that the lowest-income groups are more likely to suffer negative effects of 'risky' health behaviours than their less poor counterparts. These 'maladaptive' behaviours are not necessarily undertaken with a harmful intent, but may be regarded as coping behaviours to provide comfort or relief from stressful lives. Moreover, people in lower socio-economic classes by virtue of their life circumstances are exposed to more stressors, and with fewer resources to manage them and greater vulnerability to stressors, they are doubly victimised. Poverty is associated with many long-term problems, such as poor health and increased mortality, school failure, crime and substance misuse. The relationship between occupational class and mortality is evident from a survey in the 1970s, which showed that the mortality rate among men aged 20-64 years was almost twice as high for those in class V as for those in class I, and by the early 1990s it was almost three times as high (Drever \& Bunting, 1997) (Table 1).

\section{Poverty and psychiatric disorders}

It is not just infectious diseases that demonstrate the powerful social-epidemiological correlation; it is also psychiatric conditions, which not only occur at higher rates in the poorest areas, but also cluster together, usually in disintegrating inner-city communities. Money is not a guarantor of mental health, nor does its absence necessarily lead to mental illness. However, it is generally conceded that poverty can be both a determinant and a consequence of poor mental health (Langner \& Michael, 1963).

Table 1 Standardised mortality rates per 100000 for men aged 20-64 years in England and Wales: comparison of years 1970-72 and 1991-93

$\begin{array}{lcc}\text { Social class } & 1970-72 & 1991-93 \\ \text { I - Professional } & 500 & 280 \\ \text { II - Managerial } & 526 & 300 \\ \text { III-N - Skilled (non-manual) } & 637 & 426 \\ \text { III-M - Skilled (manual) } & 683 & 493 \\ \text { IV - Partly skilled } & 721 & 492 \\ \text { V - Unskilled } & 897 & 806 \\ \text { All classes } & 624 & 419 \\ \text { Source: Drever \& Bunting (1997) } & & \end{array}$

The relationship between low economic status and elevated incidence and prevalence of mental illness has become increasingly apparent. The New Haven study in 1958 (Hollingshead \& Redlich, 1958) and the Midtown Manhattan Study conducted a few years later (Langner \& Michael, 1963) indicated that there was a direct relationship between the experience of poverty and a high rate of emotional disturbance, as well as differential availability and use of treatment modes and facilities by different social classes. Many assume that the socio-economic class gradient with respect to disease can mostly be explained by differences in health care access.

The complexity and interrelatedness of factors such as poverty, health and employment make it interesting to look at the relationship that prevails between them. Relationships between social status and various aspects of mental disorder have long been of interest to both clinicians and researchers, and a large body of research exists showing the importance of social status in understanding psychiatric illness and disability. Epidemiological studies throughout the world have demonstrated an inverse relationship between mental illness and social class. Psychiatric disorders have been consistently shown to be more common among people in lower social classes. The prevalence of psychiatric disorders, including neurotic disorders, functional psychoses and alcohol and drug dependence, was investigated in the 1995 survey published by the Office of Population Censuses and Surveys (Meltzer et al, 1995). Employment status was a major factor in explaining the differences in prevalence rates of all psychiatric disorders in adults. Unemployment significantly increased the odds ratio of psychiatric disorders compared with the reference group. It almost quadrupled the odds of drug dependence after controlling for other socio-demographic variables. Unemployment also approximately trebled the odds of phobia and functional psychosis. It more than doubled the odds of depressive episode, generalised anxiety disorder and obsessivecompulsive disorder, and increased the odds of mixed anxiety and depressive disorder by more than two-thirds (Table 2).

\section{Psychoses}

It is well recognised that psychoses show a relationship with social class, with the highest prevalence of psychosis in both men and women found in social class V (Argyle, 1994). However, there are controversies over whether the poor social performance and lower social class of patients with schizophrenia are consequences of the illness, 
Table 2 Prevalence (\%) of psychiatric disorders according to social class, with odds ratio of employment status

\begin{tabular}{|c|c|c|c|c|c|c|c|}
\hline \multirow[t]{2}{*}{ Psychiatric disorder } & \multicolumn{5}{|c|}{ Social class } & \multirow{2}{*}{$\begin{array}{l}\text { Employed } \\
\text { adjusted } \\
\text { odds ratio }\end{array}$} & \multirow{2}{*}{$\begin{array}{c}\text { Unemployed } \\
\text { adjusted odds ratio } \\
(95 \% \mathrm{CI})\end{array}$} \\
\hline & $I$ & II & III & $I V$ & $V$ & & \\
\hline $\begin{array}{l}\text { Mixed anxiety and depressive } \\
\text { disorder }\end{array}$ & 60 & 76 & 78 & 76 & 73 & 1.00 & $1.73^{* *}(1.34-2.24)$ \\
\hline Generalised anxiety disorder & 23 & 28 & 30 & 41 & 31 & 1.00 & $2.19^{* *}(1.53-3.10)$ \\
\hline Depressive disorder & 9 & 12 & 22 & 28 & 35 & 1.00 & $2.66^{* *}(1.73-4.10)$ \\
\hline Phobia & 2 & 8 & 8 & 19 & 13 & 1.00 & $3.11^{* *}(1.65-5.80)$ \\
\hline Obsessive-compulsive disorder & 6 & 13 & 12 & 11 & 21 & 1.00 & $2.11^{* *}(1.20-3.74)$ \\
\hline Panic disorder & 1 & 9 & 8 & 7 & 12 & & \\
\hline Functional psychosis & 4 & 3 & 4 & 4 & 17 & 1.00 & $2.98^{* *}(1.18-7.47)$ \\
\hline Alcohol dependence & 33 & 34 & 47 & 58 & 73 & & \\
\hline Drug dependence & 7 & 11 & 17 & 35 & 50 & 1.00 & $3.80^{* *}(2.55-5.60)$ \\
\hline
\end{tabular}

${ }^{* *} P<0.01$.

consequences of changes in individuals predisposed to develop schizophrenia, or due to the adverse social conditions that lead to schizophrenia. The relationship between poverty and psychosis is complex, and two explanatory hypotheses have been put forward: social causation ('breeder') and social selection ('drift'). According to the social causation theory, the greater socio-economic adversity characteristic of lower-class living conditions precipitates psychosis in vulnerable individuals. However, this theory was challenged by Goldberg \& Morrison (1963) in a study showing that the social class distribution of the fathers of patients with schizophrenia did not deviate from that of the general population. The excess of low socio-economic status among people with schizophrenia was mainly attributable to individuals who had drifted down the occupational and social scale prior to the onset of psychosis.

It is possible that the relationship between class and schizophrenia exists because the conditions of life experienced by people of lower social class foster conceptions of social reality that are so limited and rigid as to impair their ability to deal resourcefully with problematic and stressful situations. Although such impairment does not in itself result in schizophrenia, in conjunction with genetic vulnerability and great stress it could be disabling.

The association between social inequality at birth and subsequent risk of schizophrenia is uncertain. Mulvany et al (2001) concluded that low social class at birth was not associated with increased risk of schizophrenia, but views remain divided on the association between social inequality and psychoses and no definite conclusion has been reached.

Brown et al (2000) studied the relationship between social class of origin and cardinal symptoms of schizophrenic disorders over the course of early illness. Patients whose origin was upper or middle social class, compared with those from the lower social class, had lower symptom levels of hallucinations and delusions. Patients from the lower social class were older at first contact with psychiatric services than those from the higher social classes; this could be explained by the fact that people from the lower social class find it more difficult to access services. Alternatively, people belonging to the higher social class might be better informed about mental illness and seek treatment early. It is also possible that the beliefs and values of people in lower socio-economic groups, such as their tolerance and acceptance of the behavioural and social aspects of the disorder, explain the observed socio-economic inequalities.

\section{Mood disorder}

Many studies have reported that low socio-economic status is associated with high prevalence of mood disorders (Dohrenwend et al, 1992). In addition, longitudinal research in Stirling County (Murphy et al, 1991) indicated that during the 1950s and 1960s the prevalence of depression was significantly and persistently higher in the low socio-economic status population than at other socio-economic status levels. Incidence of depression after the study began was also higher among those who were initially in the low socio-economic status group, supporting the view that the stress of poverty may be causally related to depression. There was also a trend for prior depression to be associated with subsequent downward social mobility, supporting the view that the concentration of people with depression at the lower end of the social hierarchy may result from disabling aspects of the illness.

A positive relationship has been found between socio-economic status and vulnerability to mood 
disorder, with higher rates of vulnerability found among individuals with lower educational and social achievement levels. The social causation hypothesis suggests that the stress associated with low social position, such as exposure to social adversity and lack of resources to cope with difficulty, might contribute to the development of mood disorder, whereas the social selection hypothesis argues that genetically predisposed individuals drift down to - or fail to rise out of such a position (Jarvis, 1971). Patients with major depressive disorder or bipolar depression were more 'downwardly mobile' than people with neurotic depression (Eisemann, 1986).

The work of Brown \& Harris (1978) points strongly to the importance of supportive relationships in protecting vulnerable women from developing depression. The effect of poverty is substantially reduced when the degree of isolation from friends and family is controlled for, suggesting that social isolation mediates some of the relationships between economic status and mood disorders (Bruce \& Hoff, 1994).

It has also been suggested that social class might have an influence on the psychopathological pattern of depressive symptoms. Patients who presented with somatisation and anxiety symptoms were more frequently from the lower social classes, whereas cognitive symptoms were more common among the upper classes. The amount of depression associated with economic hardship among adults may depend on age: Mirowsky \& Ross (2001) found that the amount of depression associated with economic hardship decreases with greater age. Economic deprivation and poor marital relationships were important risk factors for the occurrence and chronicity of depression (Patel et al, 2002). Both depression and poverty tend to be chronic, and warrant the attention of caregivers and policymakers.

\section{Suicide}

The National Confidential Inquiry into Suicide and Homicide by People with Mental Illness, along with many other studies, reported that the majority of people who completed suicide were either unemployed or had a long-term illness (Department of Health, 1999a). Compared with the general population, people who attempt suicide belong more often to the social categories associated with social destabilisation and poverty.

Gunnell et al (1995) examined the relations between suicide, parasuicide and socio-economic deprivation. A strong association was found between suicide and parasuicide, with socio- economic deprivation accounting for much of this relationship. Furthermore, homicide and suicide occur more frequently in highly populated, deprived areas (Kennedy et al, 1999). This finding is also supported by Crawford \& Prince (1999), who noted increasing rates of suicide in young unemployed men living in conditions of extreme social deprivation. It is also true that the mortality rates of overdoses involving cocaine and opiates are significantly associated with poverty status (Marzuk et al, 1997).

\section{Alcohol and substance misuse}

Alcohol and drug dependence fit in with the general pattern, with high rates found among those in social class V. Among men and women, alcohol and drug dependence are both much higher among the unemployed group. Social class is a risk factor for alcohol-related mortality, which is also linked to social structural factors such as poverty, disadvantage and social class (Harrison \& Gardiner, 1999). Alcohol-related mortality rates are higher for men in the manual occupations than in the nonmanual occupations, but the relative magnitude depends on age. Men aged 25-39 years in the unskilled manual class are 10-20 times more likely to die from alcohol-related causes than those in the professional class, whereas men aged 55-64 years in the unskilled manual class are only about 2.5-4 times more likely to die than their professional counterparts.

For women, younger women in the manual classes are more likely to die from alcohol-related causes, but among older women it is those in the professional class who have the greater mortality. Hans (1999) studied the demographic and psychosocial characteristics of substance-misusing pregnant women, and found that demographic features were related only to type of substance used, with Black women and poorer women more likely to use illicit substances, particularly cocaine, and White women and better-educated women more likely to use alcohol.

\section{Personality disorders}

The relationship between low socio-economic status and personality disorders has not been extensively studied. However, there is some evidence that personality disorders are more frequent among single individuals from lower socio-economic classes in inner cities. Studies focusing on antisocial personality disorder have shown that it too is found more commonly in people belonging to lower socioeconomic classes. 
Low family income and poor housing predict official and self-reported juvenile and adult offending. However, the relationship between poverty and criminality is complex and continuous. The interaction between impulsivity and neighbourhood on criminal activities indicates that the effects of impulsivity are stronger in poorer neighbourhoods than in better-off ones (Lynam et al, 2000). In severely disadvantaged settings, even quite young children may be directly exposed to community violence (Osofsky, 1995).

In the Cambridge Study in Delinquent Development, an unstable job record at the age of 18 years was an important independent predictor of young men's convictions between the ages of 21 and 25 (Farrington, 1995). In addition, having an unskilled manual job at the age of 18 was an independent predictor of adult social dysfunction and antisocial personality at the age of 32 . Between the ages of 15 and 18 , young males in this study were convicted at a higher rate when they were unemployed than when they were employed, suggesting that unemployment is associated with crime. It seems likely that financial need is an important link in the causal chain between unemployment and crime.

\section{Personality disorder or criminality?}

It is interesting to note that the major criticism of the DSM-III-R criteria for antisocial personality disorder (American Psychiatric Association, 1987) was that personality traits or symptoms of psychopathy were neglected and that the disorder was conceptualised as synonymous with criminality. However, the criteria for the disorder in DSM-IV (American Psychiatric Association, 1994), and also in ICD-10 (World Health Organization, 1992), reflect personality traits more than overt criminal behaviour.

\section{Effect of poverty on children}

Psychiatric disorders of childhood result from the interplay between genetic and environmental factors. The link between adverse experiences and childhood disorder is complex and involves reciprocal effects from children, as they are not just passive recipients of experience. There is a growing body of research relating to poverty and health indicating that low income combined with disruptive demographic factors and poor external support generate the stress and life crises that put children at risk, and may precipitate psychiatric disorders in childhood.

Children in the poorest households are three times more likely to have a mental illness than children in the best-off households (Department of Health, 19996 ). Poverty and social disadvantage are most strongly associated with deficits in children's cognitive skills and educational achievements (Duncan \& Brooks-Gunn, 1997). In the behavioural domain, conduct disorder and attention-deficit hyperactivity disorder show links with family poverty, and this is most marked for children in families facing persistent economic stress. The relationship between poverty and childhood disorder appears to be more marked for boys than for girls, and seems to be stronger in childhood than in adolescence. Rates of childhood disorder vary in different neighbourhoods and communities. Early studies in the UK suggested that risks of disorder in inner-city areas were twice those in small towns (Rutter et al, 1975).

It is well recognised that conduct disorder is three to four times more common in children who live in socio-economically deprived families with low income, or who live in a poor neighbourhood. The mechanisms that place poor children at increased risk of psychiatric disorder may have to do primarily with increased rates of parental and family characteristics associated with child psychiatric disorder, rather than the economic disadvantage itself. With regard to economic disadvantage, persistent poverty should be distinguished from current poverty: persistent poverty significantly predicts internalising symptoms such as childhood depression, whereas just current poverty predicts externalising symptoms such as childhood behavioural disorders. It is likely that poverty imposes stress on parents and that this inhibits family processes of informal social control, in turn increasing the risks of harsh parenting and reducing parents' emotional availability to meet their children's needs.

Kaplan et al (2001) looked at childhood socioeconomic position and cognitive function in adulthood and concluded that higher socioeconomic position during childhood and greater educational attainment are both associated with cognitive function in adulthood, with mothers and fathers each contributing to their offspring's formative cognitive development and later-life cognitive ability. Improvements in both parental socio-economic circumstances and the educational attainment of their offspring could possibly enhance cognitive function and decrease the risk of dementia later in life.

Erratic, threatening and harsh discipline, lack of supervision and weak parent-child attachments mediate the effects of poverty and other structural factors on delinquency. In the Cambridge Study in Delinquent Development, one of the most important 
childhood predictors of delinquency was poverty (Farrington, 1995). Poverty was also found to have an effect on both academic failure and extreme delinquency when maternal education and early childhood behaviour were controlled for (Pagani et al, 1999). Eyler \& Behnke (1999) studied the outcome during the first 2 years in children prenatally exposed to the most commonly used drugs of misuse, and concluded that the effects of drugs appear to be exacerbated in children living in poverty.

\section{Health inequalities - explanatory models}

We have argued that economic distress has significant effects on health indicators. How might such effects be mediated? The Black Report (Townsend et al, 1992) highlights various explanations for the existing health inequalities, dividing them into four categories: artefact explanations; theories of natural or social selection; materialist or structuralist explanations; and cultural and behavioural explanations.

\section{Artefact theory}

The artefact theory suggests that both class and health are artificial variables, and that the relationship between them may itself be an artefact. It is believed that the failure to reduce the gap between classes has been counterbalanced by the shrinkage in the relative size of the lower socio-economic classes themselves.

\section{Natural selection}

Theories of natural or social selection relegate occupational class to the status of dependent variable, and health acquires the greater degree of causal significance. This explanation suggests that social class I has the lowest rate of premature mortality because it is made up of the strongest and most robust men and women in the population, and that class $\mathrm{V}$ has the weakest people. It puts forward the idea that poor health carries low social worth as well as low economic reward, but that these factors do not do not cause the high mortality.

\section{Materialist theories}

Materialist or structuralist explanations emphasise the role of economic and associated socio-structural factors in the distribution of health. It is difficult to ascribe the premature mortality in the lower socioeconomic class to subsistence poverty. Social class and the characteristics associated with belonging to that class have health implications. As poverty is a relative concept, people belonging to a low socioeconomic class may be relatively disadvantaged in relation to the risks of illness or accident, or to the factors that promote a healthy lifestyle.

\section{Behavioural theories}

The cultural or behavioural explanations of the distribution of health suggest that its unequal distribution in modern industrial society is the result of incautious lifestyles, wherein people harm themselves or their children by their excessive consumption of harmful commodities and refined foods, and by their underutilisation of preventive health care and contraception. It is implied that there are subcultural lifestyles, rooted in personal characteristics and level of education, which govern behaviour. According to the 'culture of poverty' view of Oscar Lewis (1967), human existence in any given environment involves a process of biological and social adaptation which gives rise to the elaboration of a structure of norms, ideas and behaviours. This 'culture of poverty' over time seems to help individuals to cope with their environment. This view firmly ascribes poor health to the behaviour of people themselves, and by implication makes them fully responsible for the untoward outcomes. The implication that the poor are in some respects a homogeneous group has caused this view to be widely criticised by British social scientists (Rutter \& Madge, 1976; Holman, 1978; Townsend, 1979).

\section{Discussion}

Social inequality and poverty have demonstrable adverse effects on health. These effects are, in our view, amenable to remediation. In the UK, the National Health Service has several interlinked responsibilities in relation to health inequalities, which include the provision of equity of access to effective health care. One of the recommendations of the Independent Inquiry into Inequalities in Health (Acheson, 1998) was that as part of health impact assessment, all policies likely to have a direct or indirect effect on health should be evaluated in terms of their impact on health inequalities. These policies should be formulated in such a way that by favouring those who are less well-off, they should ultimately reduce such inequalities. In the consultation document Tackling 
Box 1 National targets for reducing health inequalities (Department of Health, 2001)

Infant mortality Starting with children under 1 year old, by 2010 to reduce by at least $10 \%$ the gap in mortality between manual groups and the population as a whole

Life expectancy Starting with health authorities, by 2010 to reduce by at least $10 \%$ the gap between the fifth of areas with lowest life expectancy at birth and the population as a whole

Child poverty To work towards the eradication of child poverty by reducing the number of children living in poverty by a quarter by 2004

Smoking To reduce smoking rates among manual groups from $32 \%$ in 1998 to $26 \%$ by 2010 , so that we can narrow the gap between manual and non-manual groups

Teenage pregnancy By achieving agreed local conception reduction targets, to reduce the national under-18 conception rate by $15 \%$ by 2004 and $50 \%$ by 2010

Health Inequalities (Department of Health, 2001), the Government has set nationa targets for doing this (Box 1).

On a global level, the Development Assistance Committee of the Organisation for Economic Cooperation and Development has called for a global partnership to pursue a new development strategy focused on poverty and social goals (Development Assistance Committee, 1996), and the World Bank suggests various ways of responding to poverty (Box 2). The poverty goal is to halve the proportion of people in extreme poverty by 2015. This is expected to be achieved by accelerating economic growth and by improving the distribution of income and wealth. The social goals include reducing infant mortality by two-thirds by 2015 , achieving universal primary education in all countries, providing access to reproductive health services for all by 2015, and making progress towards gender equality by 2005 . To achieve these goals, international agencies must support countries that show interest and determination to take up the challenges of the goals for the 21st century, and must strengthen their capacity to monitor progress. In order to build a successful economy, new challenges have to be met with resilence, fresh thinking and courage. This will enable us to make long-term decisions and progress towards a better world.

\section{References}

Acheson, D. (1998) Independent Inquiry into Inequalities in Health: Report. London: Stationery Office.

American Psychiatric Association (1987) Diagnostic and Statistical Manual of Mental Disorders (3rd edn, revised) (DSM-III-R). Washington, DC: APA.

American Psychiatric Association (1994) Diagnostic and Statistical Manual of Mental Disorders (4th edn) (DSM-IV). Washington, DC: APA

Argyle, M. (1994) The Psychology of Social Class. London: Routledge.

Brown, G. W. \& Harris, T. (1978) Social Origins of Depression: A Study of Psychiatric Disorders in Women. London: Tavistock.

Brown, A. S., Susser, E. S., Jandorf, L., et al (2000) Social class of origin and cardinal symptoms of schizophrenic disorders over the early illness course. Social Psychiatry and Psychiatric Epidemiology, 35, 53-60.

Bruce, M. L. \& Hoff, R. A. (1994) Social and physical health risk factors for first-onset major depressive disorder in a community sample. Social Psychiatry and Psychiatric Epidemiology, 29, 165-171.

Crawford, M. J. \& Prince, M. (1999) Increasing rates of suicide in young men in England during the 1980s: the importance of social context. Social Science and Medicine, 49, 14191423.

Department of Health (1999a) National Confidential Inquiry into Suicide and Homicide by People with Mental Illness. London: Department of Health.

Department of Health (1999b) Saving Lives: Our Healthier Nation. London: Stationery Office.

\section{Box 2 Responding to poverty (World Bank Group, 2004)}

Poverty can be fought by:

- improving the distribution of income and wealth and, more importantly, learning about the impact of policies on income distribution;

- accelerating social development, which includes education of girls and women, provision of safe water and sanitation, child immunisation, and the provision of safety nets to protect the most vulnerable;

- international agencies that support countries showing a determination to take up the challenges of the goals for the 21st century

- international agencies that work with developing countries to strengthen each country's capacity to monitor progress on outcomes;

- accelerating economic growth, which will require policies that encourage macroeconomic stability, shift resources to more efficient sectors, and integrate with the global economy. 
Department of Health (2001) Tackling Health Inequalities: Consultation on a Plan for Delivery. London: Department of Health.

Department of Health (2003) Tackling Health Inequalities: A Programme for Action. London: Department of Health.

Development Assistance Committee (1996) Shaping the 21st Century. The Contribution of Development Co-operation. Paris: Organisation for Economic Co-operation and Development.

Dohrenwend, B. P., Levav, I., Shrout, P. E., et al (1992) Socioeconomic status and psychiatric disorders: the causation-selection issue. Science, 255, 946-952.

Drever, F. \& Bunting, J. (1997) Patterns and trends in male mortality. In Health Inequalities: Decennial Supplement (eds F. Drever \& M. Whitehead). DS series no. 15. London: Stationery Office.

Duncan, G. J. \& Brooks-Gunn, J. (eds) (1997) Consequences of Growing Up Poor. New York: Russell Sage.

Eisemann, M. (1986) Social class and social mobility in depressed patients. Acta Psychiatrica Scandinavica, 73, 399402.

Eyler, F. D. \& Behnke, M. (1999) Early development of infants exposed to drugs prenatally. Clinical Perinatology, 26, 107150.

Farrington, D. P. (1995) The development of offending and antisocial behaviour from childhood: key finding from the Cambridge Study in Delinquent Development. Journal of Child Psychology and Psychiatry, 36, 929-964.

Goldberg, E. M. \& Morrison, S. L. (1963) Schizophrenia and social class. British Journal of Psychiatry, 109, 785-802.

Gunnell, D. J., Peters, T. J., Kammerling, R. M., et al (1995) Relation between parasuicide, suicide, psychiatric admissions and socioeconomic deprivation. BMJ, 311, $226-230$

Hans, S. L. (1999) Demographic and psychosocial characteristics of substance-abusing pregnant women. Clinical Perinatology, 26, 55-74.

Harrison, L. \& Gardiner, E. (1999) Do the rich really die young? Alcohol-related mortality and social class in Great Britain, 1988-94. Addiction, 94, 1871-1880.

Hodes, M. (2002) Implications for psychiatric services of chronic civilian strife: young refugees in the UK. Advances in Psychiatric treatment, 8, 366-374.

Hollingshead, A. B. \& Redlich, F. C. (1958) Social Class and Mental Illness: A Community Study. New York: John Wiley.

Holman, R. T. (1978) Poverty: Explanations of Social Deprivation. London: Robertson.

Jarvis, E. (1971) Insanity and Idiosy in Massachusetts: Report of the Commission of Lunacy, 1855. Cambridge, MA: Harvard University Press.

Kaplan, G. A., Haan, M. N, Syme, S., et al (1987) Socioeconomic status and health. In Closing the Gap: The Burden of Unnecessary Illness (eds R. W. Amler \& H. B. Dull), pp. 125-129. New York: Oxford University Press.

Kaplan, G. A., Turrell, G., Lynch, J. W., et al (2001) Childhood socioeconomic position and cognitive function in adulthood. International Journal of Epidemiology, 30, 256263.

Kennedy, H. G, Iveson, R. C. \& Hill, O. (1999). Violence, homicide and suicide: strong correlation and wide variation across districts. British Journal of Psychiatry, 175, 462-466.

Langner, T. S. \& Michael, S. T. (1963) Life Stress and Mental Health. London: Collier-Macmillan.

Lewis, O. (1967) The Children of Sanchez. New York: Random House.

Lynam, D. R., Caspi, A., Moffitt, T. E, et al (2000) The interaction between impulsivity and neighbourhood context on offending: the effects of impulsivity are stronger in poorer neighbourhoods. Journal of Abnormal Psychology, 109, 563-574.

Marzuk, P. M., Tardiff, K., Leon, A. C., et al (1997) Poverty and fatal accidental drug overdoses of cocaine and opiates in New York City: an ecological study. American Journal of Drug and Alcohol Abuse, 23, 221-228.

Meltzer, H., Gill, B., Petticrew, M., et al (1995) OPCS Surveys of Psychiatric Morbidity in Great Britain: 1995. London: HMSO.
Mirowsky, J. \& Ross, C. E. (2001) Age and the effect of economic hardship on depression. Journal of Health and Social Behaviour, 42, 132-150.

Mulvany, F., O'Callaghan, E., Takei, N., et al (2001) Effect of social class at birth on risk and presentation of schizophrenia: case-control study. BMJ, 323, 1398-1401.

Murphy, J. M., Oliver, D. C., Monson, R. R., et al (1991) Depression and anxiety in relation to social status: a perspective epidemiological study. Archives of General Psychiatry, 48, 223-229.

Nolan, P. \& Smojkis, M. (2003) The mental health of nurses in the UK. Advances in Psychiatric Treatment, 9, 374379 .

Osofsky, J. D. (1995) The effects of exposure to violence on young children. American Psychologist, 50, 782-788.

Pagani, L., Boulerice, B., Vitaro, F., et al (1999) Effects of poverty on academic failure and delinquency in boys: a change and process model approach. Journal of Child Psychology and Psychiatry, 40, 1209-1219.

Patel, V., Rodrigues, M. \& DeSouza, N. (2002) Gender, poverty, and postnatal depression: a study of mothers in Goa, India. American Journal of Psychiatry, 159, 43-47.

Rutter, M. \& Madge, N. (1976) Cycles of Disadvantage. London: Heinemann.

Rutter, M., Yule, B., Quinton, D., et al (1975) Attainment and adjustment in two geographical areas. III: Some factors accounting for area differences. British Journal of Psychiatry, 126, 520-533.

Smith, G. D., Bartly, M. \& Blane, D. (1990) The Black Report on socioeconomic inequalities in health: 10 years on. $B M J$, 301, 373-377.

Townsend, P. (1979) Poverty in the United Kingdom. London: Penguin.

Townsend, P., Davidson, N. \& Whithead, M. (eds) (1992) The Black Report and the Health Divide: Inequalities in Health (2nd edn). London: Penguin.

Tribe, R. (2002) Mental health of refugees and asylumseekers. Advances in Psychiatric Treatment, 8, 240-248.

Wilkinson, R. G. (1996) Unhealthy Societies: The Afflictions of Inequality. London: Routledge.

Wilkinson, R. G. (1997) Health inequalities: relative or absolute material standards. BMJ, 314, 591-595.

World Bank Group (2004) Responding to Poverty: How to Move forward in Achieving the Millennium Development Goals? Washington, DC: World Bank Group. http:// www.worldbank.org/poverty/mission/rp1.htm

World Health Organization (1992) Tenth Revision of the International Classification of Diseases and Related Health Problems (ICD-10). Geneva: WHO.

World Health Organization (1995) Bridging the Gaps. Geneva: WHO.

\section{Multiple choice questions}

1 Poverty:

a the poverty line is the minimum income level necessary to meet basic needs

$\mathrm{b}$ the World Bank uses poverty lines based on the norms defined for each society

c poverty and social inequality are closely linked

d poverty affects mental and social well-being

e the gap between the poor and rich of the world is narrowing.

\section{Poverty and psychiatric disorders:}

a the effect of poverty is substantially reduced when the degree of isolation from friends and family is controlled for

b employment status is a major factor in understanding the differences in prevalence rates of all psychiatric disorders in adults 
c according to the social causation theory, the excess of low socio-economic status among patients with schizophrenia is mainly attributable to individuals who drift down the occupational and social scale before the onset of psychosis

$\mathrm{d}$ homicide and suicide are less frequent in highly populated deprived areas

e alcohol-related mortality rates are higher for men in the manual occupations than in non-manual occupations.

3 Poverty and childhood psychiatric disorder:

a poverty is strongly associated with deficits in children's cognitive skills and educational achievements

b disruptive behaviours are most marked in children of families facing persistent economic stress

c inner-city areas have double the risks of childhood psychiatric disorder compared with small towns

d the relationship between poverty and childhood disorder seems to be more marked for boys than for girls e children in the poorest households are three times more likely to have mental illness than children in the richest households.

4 Poverty and delinquency:

a the effects of impulsivity are stronger in poorer neighbourhoods than in better-off neighbourhoods

b boys were found to be convicted at a lower rate when they were unemployed than when they were employed

c one of the most important childhood predictors of delinquency is poverty

d erratic, threatening and harsh discipline, low supervision and weak parent-child attachments mediate the effects of poverty and other structural factors on delinquency

e in the Cambridge Study, an unstable job record of a young man at the age of 18 years was an important predictor of his later convictions.

\section{Young People and Substance Misuse}

\section{Edited by llana Crome, Hamid Ghodse, Eilish Gilvarry and Paul McArdle}

Substance misuse is one of the most common and serious yet preventable risks to a young person's health and development. This book provides an overview of the consequences of substance misuse, the interventions and services available, and, most importantly, the way forward for improving treatment and services. Young People and Substance Misuse brings international expertise together with a UK health care perspective. It will give the reader an in-depth understanding of the issues as well as suggesting practical solutions to a problem that affects so many aspects of the well-being of teenagers.

This is a book for all those who need to know more about the options for prevention and treatment - teachers, carers, parents, researchers and policy-makers as well as those working in the criminal justice system, social services and mental health care.

The book includes expert analysis of:

- Prevalence and routes to drug use

- Misuse of illicit drugs, alcohol and tobacco

- Parental, family and social influences

- Treatment and prevention strategies.

February 2004, Paperback, 240pp, ISBN 190467101 2, Price $£ 15.00$

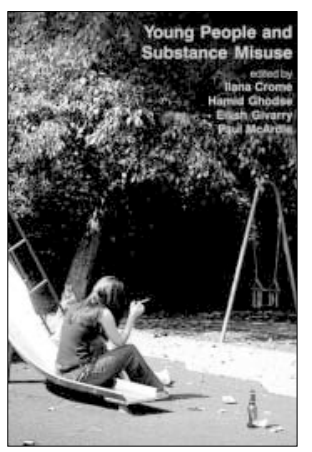

